\title{
Control Groups Appropriate for Behavioral Interventions
}

\author{
WILLIAM E. WHITEHEAD \\ Center for Functional GI and Motility Disorders, University of North Carolina at Chapel Hill, Chapel Hill, North Carolina
}

There are 4 sources of bias in clinical trials: investigator bias, patient expectation (placebo response), ascertainment bias (inadvertent selection of an unrepresentative sample), and nonspecific effects such as the normal waxing and waning of symptoms over time and the quality of the doctor-patient relationship. In drug trials, these biases are adequately controlled by comparing active to inert pills, randomly assigning subjects to treatments, blinding both the investigator and subject to group assignment, and testing subjects at multiple sites. However, there are special problems with conducting clinical trials of behavioral or psychological interventions that render these controls inadequate. It is impossible to blind the experimenter to which treatment is active, it is difficult to identify a control treatment that is inactive but just as credible to the subject, and doctor-patient relationship variables are more important than in drug trials. The inability to blind the experimenter can be circumvented by having an independent, blinded investigator assess the outcome, and doctor-patient effects can be controlled by using multiple, experienced therapists. The most difficult problem, identifying an appropriate control treatment, can be solved by adhering to 2 principles: the control treatment should be plausible, and it should not have a significant impact on the mechanism that is thought to explain the effectiveness of the investigational treatment. Investigators should confirm that these 2 goals have been achieved by monitoring expectation of benefit with a treatment credibility questionnaire, measuring changes in process variables (variables that reflect the presumed mechanism of treatment), and monitoring differential dropout rates.

$\mathrm{T}$ he purpose of a controlled clinical trial is to determine whether a treatment has specific value that is due to a hypothesized mechanism of action and is not attributable to nonspecific effects (i.e., sources of bias). A clinical trial differs from usual clinical care. In a clinical practice, providers normally take advantage of nonspecific effects such as patient education, a good doctorpatient relationship, and a positive expectation of benefit to maximize patient improvement. Moreover, usual clinical practice places less responsibility on patients for keeping symptom records and coming in for checkups. Because of these differences, clinical trials seem to underestimate the effectiveness of new treatments relative to what clinicians expect; therefore, large numbers of patients need to be studied.

Because controlled clinical trials are so costly, they should only be conducted when there is already evidence from uncontrolled trials that the treatment is likely to be more effective (or at least equally effective and cheaper) than current therapy, and they should only be initiated when the investigators have a clear hypothesis about how the new treatment works. The importance of having an a priori hypothesis about the mechanism of action will become apparent.

\section{Do Incontinence Treatment Trials Require Controls for Placebo Effects?}

Investigators sometimes assume that it is not necessary to carry out controlled trials for incontinence because fecal and urinary incontinence are such objective outcomes that patient expectations (placebo effects) and investigator bias are unlikely to significantly affect the outcome. From this perspective, enrolling patients who have failed to respond to standard medical management in an uncontrolled trial would appear to be adequate for measuring outcomes. However, this is clearly not the case. Table $1^{1-11}$ shows that a wide range of behavioral interventions have been recommended for the treatment of incontinence, many of which are highly susceptible to expectation effects. As 1 very clear example indicates, Freeman and Baxby ${ }^{11}$ reported that hypnosis eliminated urinary incontinence associated with detrusor instability in $58 \%$ of patients and improved another $28 \%$; these reductions in incontinence were associated with improved cystometrograms in the majority of patients.

(C) 2004 by the American Gastroenterological Association 0016-5085/04/\$30.00 doi:10.1053/j.gastro.2003.10.038 
Table 1. Behavioral Treatments for Fecal and Urinary Incontinence

\begin{tabular}{|c|c|}
\hline Intervention & Results \\
\hline Biofeedback & $\begin{array}{l}50 \% \text { of patients resolved fecal } \\
\text { incontinence and } 25 \% \\
\text { improved } 1,2 \text {; biofeedback } \\
\text { superior to drug treatment for } \\
\text { urge urinary incontinence }{ }^{3}\end{array}$ \\
\hline Sensory training & $\begin{array}{l}\text { Impaired rectal sensation } \\
\text { associated with fecal } \\
\text { incontinence; sensory training } \\
\text { improved continence }{ }^{4-6}\end{array}$ \\
\hline Kegel exercises alone & $\begin{array}{l}\text { Meta-analysis supports efficacy of } \\
\text { pelvic floor exercises for stress } \\
\text { urinary incontinence }^{7}\end{array}$ \\
\hline $\begin{array}{l}\text { Verbally guided sphincter } \\
\text { training }\end{array}$ & $\begin{array}{l}\text { Equal to biofeedback for } \\
\text { constipation }^{8} \text { and fecal } \\
\text { incontinence }^{9}\end{array}$ \\
\hline Education & $\begin{array}{l}30 \% \text { resolved incontinence } \\
\text { equivalent to biofeedback }\end{array}$ \\
\hline $\begin{array}{l}\text { Hypnosis for urge urinary } \\
\text { incontinence }\end{array}$ & $\begin{array}{l}58 \% \text { symptom free; } 28 \% \\
\quad \text { improved }^{11}\end{array}$ \\
\hline
\end{tabular}

Nonspecific treatment effects can also confound the results of incontinence treatment trials, as shown in a report by Heymen et al. ${ }^{10}$ These investigators enrolled only patients who had failed all medical management of fecal incontinence; instead of placing them immediately in a behavioral program, they entered all patients in a 1-month run-in trial, during which education and good medical management were instituted. The patients may also have received more time and attention from the investigators than they had previously received from their family physicians. The result was that $30 \%$ of subjects resolved their incontinence during the run-in period. ${ }^{10}$

\section{Types of Bias That Clinical Trials Seek to Control}

\section{Investigator Bias}

It is a well-accepted principle that the investigator should not decide which patients are assigned to the experimental and control groups because in so doing it would be nearly impossible to avoid biasing the study. To protect against bias, patients are normally assigned to groups by using a prearranged sequence of random numbers. The investigator should not be aware of the next group assignment when screening a patient for enrollment because he/she might unconsciously influence group assignment through a biased decision regarding whether the patient meets the inclusion criteria.

\section{Patient Expectation (Placebo Response)}

The patient's confidence level that the treatment to which he/she has been assigned will be effective can profoundly influence the outcome of the trial. In drug trials for irritable bowel syndrome (IBS), for example, placebo responses of up to $80 \%$ have been reported. ${ }^{12}$ The placebo response is incompletely understood, ${ }^{13}$ but some aspects of it are clear. For example, patients will be inclined to evaluate their outcomes more positively if they believe they are in the active treatment arm, and they may be more motivated to comply with homework assignments if they believe the treatment will be effective.

\section{Ascertainment Bias}

Self-selection for treatment. If patients are given a choice between an active treatment and placebo, most of them try to increase their chances of getting the active treatment. In addition, those assigned to the inactive treatment arm have less motivation to complete assignments and lower expectation of improvement. In drug studies, ascertainment bias can be controlled for by insuring that patients are blinded to their treatment assignment, but this is often not feasible with behavioral interventions.

Other types of self-selection bias are less obvious and are more difficult to control by blinding. Through various forms of publicity, clinics or individual providers may become well known for providing specific types of treatment. The patients who seek out these providers or settings may be less motivated, and they may have lower expectation of benefit if they are assigned to a different treatment. Moreover, the patients who seek out specialized treatments may be atypical of the total population of patients with the disorder.

Change in the subject pool over time. Clinical trials may extend over years. During this time, the types of patients attending the clinic may change, especially if there is media publicity about the trial or if new treatments become available. To minimize the impact of changes in the subject pool over time, subjects are usually randomized in relatively small blocks to ensure that comparable numbers of subjects are assigned to all arms of the study at each stage of the investigation.

Differential dropout rate. Patients are more likely to drop out of a trial if their condition is not improving; the resulting effect is that more people drop out of the control arms of studies compared with the active treatment arms. Unless the dropouts are retained in the data analysis and labeled treatment failures, this differential dropout rate can seriously bias outcomes. A different problem can occur in a behavioral intervention study if the subjects are not randomized to the treatment group they prefer: the subjects may drop out of the study before beginning treatment. It is appropriate to exclude these 
patients from the analysis because they were not exposed to treatment; however, significant numbers of dropouts may result in important differences between the treatment and control groups.

\section{Nonspecific Effects}

Doctor-patient relationship. In the course of treating incontinence, physicians provide education and advice on exercise and diet. They may also evaluate the impact of medications the patient is taking and make adjustments when necessary. These nonspecific aspects of treatment may be helpful even if they are not regarded as part of the treatment regimen being evaluated. ${ }^{10}$ When patients enter a trial, the physician or research coordinator is likely to pay increased attention to these nonspecific factors, which may improve outcomes.

In addition to these nonspecific treatment effects, the quality of the relationship between the physician and patient, particularly the physician's authority and sympathetic interest, can influence the outcome of treatment. ${ }^{14}$ The placebo response is greater in clinical trials in which the physician meets with the patient at all follow-up visits than it is in trials in which a research coordinator meets with the patients or when the pills are mailed to the patient. ${ }^{15}$

Regression to the mean (natural history of the disease). Chronic disorders such as incontinence tend to vary in their severity over time. Patients are more likely to seek treatment, and to be enrolled in clinical trials, when their symptoms are more severe, and symptom severity may decrease simply as a result of the passage of time.

\section{Controlling for Bias in Drug Trials}

Clinical trials to evaluate the efficacy of new drugs are carried out frequently and are critically evaluated by the United States Food and Drug Administration. As a result, standards for conducting drug trials have evolved to deal with most sources of bias. The consensus is that these trials should be randomized, double-blinded, parallel group, placebo-controlled, multicenter studies. Randomization of patients to treatment by a process in which neither the investigator nor the patient has any foreknowledge of group assignment minimizes the opportunities for investigator bias and self-selection bias. Keeping both the investigator and the patient blinded to group assignment throughout the trial minimizes investigator bias, placebo effects, and nonspecific treatment effects. Parallel-group designs are preferable to crossover designs because they avoid confounding the interpretation of the data by carry-over effects and minimize unblinding of the study by side effects. Placebo control groups are used to minimize expectation effects. Recruiting patients from multiple centers or using multiple therapists from the same center minimizes the possibility that nonspecific aspects of the doctor-patient relationship will confound the study and makes it easier to accrue large samples rapidly.

\section{Special Problems With Designing Control Groups for Behavioral Interventions}

\section{It Is Not Possible to Blind the Investigator as to Which Treatment the Patient Is Assigned and Whether It Is the Active Treatment or the Control Treatment}

To compensate for the increased risk of investigator bias, trials can be designed to (1) use multiple therapists and have the data analyzed in a way that tests for differences between therapists and (2) use independent, blinded evaluators for assessment of outcome(s).

\section{It Is Difficult to Identify a Control Intervention That Is Inactive but Equally Credible}

If an inactive but credible control cannot be identified, it will be difficult to distinguish true treatment effects from placebo (expectation) effects. Some ingenious approaches to designing placebo controls have been proposed, and these are discussed later. However, the 2 most critical steps for insuring the adequate control of placebo effects are (1) administering a test (e.g., the Credibility Scale) after the initial exposure to the assigned treatment that measures the credibility of the intervention and the subject's level of expectation of positive benefit ${ }^{16}$ and (2) using process measures to assess whether the behavioral intervention is changing the physiological or psychological response it is supposed to modify, such as a change in muscle strength or sensory threshold. One should be able to show that the hypothesized process is occurring in the active treatment group and not occurring-or occurring to a lesser degree-in the control group. Ideally, it should also be possible to correlate changes in the process measure to symptom improvement. A third step that can help to preserve the credibility of the treatments is to pay close attention to how the project is titled, advertised, and described in the consent form to minimize cuing patients about which treatment arm is the active one. We have taken the precaution of developing separate consent forms for the active and control treatments and have found that institutional review boards for the protection of human subjects tolerate this process. 


\section{Doctor-Patient Relationship Variables Are More Important in Behavioral Trials}

In behavioral interventions, the goal may be to change cognitive attributions, increase perceptual vigilance (awareness of rectal sensation), motivate the patient to change habits or perform muscle strengthening exercises, or decrease stress-related physiological arousal. The amount of contact with the therapist, the status of the therapist, and the quality of the relationship can influence these outcomes. It is frequently recommended to investigators that they (1) have the same therapists provide both the active and inactive treatments, (2) use multiple therapists, and (3) ensure that the amount of contact time is identical for the active and inactive treatment arms. However, strict adherence to equal contact time may reduce the credibility of the control condition by making the therapy situation too artificial. For example, if the active treatment is interpersonal therapy involving an initial 3-hour marathon session with the patient and the control condition is standard medical care ${ }^{17}$ adherence to the equal-time requirement would be impossible or at least highly artificial. The primary consideration is to make the control condition credible to the patient.

\section{Control Groups for Behavioral Treatment Trials}

\section{Waiting-List (Delayed Start) Control Group}

Investigators sometimes randomize their patients to one group that immediately begins the investigational treatment and a second group that monitors symptoms for a period of time equivalent to the time required for the intervention in the first group before beginning the treatment. This approach does control for nonspecific treatment effects such as regression to the mean. However, this is the worst possible control for placebo effects because no one expects to improve while they are waiting to begin treatment; this situation creates a negative expectation of improvement, which may artificially amplify the difference between the active (immediate) and control (delayed start) groups.

\section{Standard Medical Management}

A number of studies have compared behavioral interventions for treatment of IBS to standard medical care. ${ }^{17,18}$ However, this is also a poor control for placebo effects because patients will normally be referred to the study only if they are perceived to have failed standard medical management. Consequently, being assigned to "more of same treatment" is likely to be associated with a negative expectation for improvement.

\section{Pill Placebo}

In their initial controlled trial of hypnosis for the treatment of IBS, Whorwell et al. ${ }^{19}$ gave a placebo capsule to control subjects. Placebo capsules may be an acceptable way of controlling for the patient's expectation of improvement, but a few precautions should be observed. First, the patient must be provided with a rationale as to why a drug would work to improve the condition. Additionally, to be able to state in the consent form that the pills could help, at least a few of the patients should receive an active drug. A disadvantage of placebo pill control groups is that patients who are attracted to the trial because they want to try a behavioral intervention may be reluctant to take a drug instead.

\section{False Feedback}

Biofeedback is a frequently used behavioral intervention for incontinence, and investigators have tried to design placebo controls for it. An approach that has been used for headache treatment, but not for incontinence, is to provide visual or auditory feedback that appears to be contingent on the patient's muscle tension, although it is in fact contingent on the muscle tension of a different patient. This approach is no longer used because it is too easy for patients to discover that the feedback display is unrelated to their own physiological responses; they only have to take a deep breath or intentionally tense their muscle to see if this action changes the feedback display. ${ }^{20}$

\section{Biofeedback Training on a Different Physiological Response}

A good solution to providing a control for biofeedback training is to train patients to control an irrelevant physiological response that they believe might reduce their symptoms. For example, in 1 study, patients were asked to decrease the alpha frequency band in their electroencephalogram ${ }^{21}$ - a response that, on the basis of media accounts, they believed would decrease vascular headaches but that was, in fact, counterproductive or irrelevant.

\section{Comparison to Alternative Treatments That Are Cheaper or Less Effective}

Several trials have compared biofeedback training for incontinence to Kegel exercises ${ }^{22-24}$ or to verbal guidance in contracting the pelvic floor muscles. ${ }^{9}$ If properly presented, these alternative treatments may be as credible to patients as biofeedback. In a landmark study of cognitive behavior therapy for IBS, Payne and 
Blanchard ${ }^{25}$ used a patient support group as the control condition because patients found this to be a plausible treatment for their bowel symptoms despite the fact that there is no objective evidence that such treatment improves IBS symptoms.

\section{Summary}

As the aforementioned examples show, it is possible to design credible control groups for behavioral interventions provided that investigators adhere to 2 principles: (1) the control group treatment should be plausible to patients, and (2) the control group treatment should not have a significant impact on the mechanism that is thought to explain the effectiveness of the investigational treatment. Investigators should confirm that these 2 goals have been achieved by monitoring expectation of benefit, measuring changes in process variables, and monitoring differential dropout rates.

\section{References}

1. Heymen S, Jones KR, Ringel $\mathrm{Y}$, Scarlett $\mathrm{Y}$, Whitehead WE. Biofeedback treatment of fecal incontinence: a critical review. Dis Colon Rectum 2001;44:728-736.

2. Norton C, Kamm MA. Outcome of biofeedback for faecal incontinence. Br J Surg 1999;86:1159-1163.

3. Burgio KL, Locher JL, Goode PS, Hardin JM, McDowell BJ, Dombrowski M, Candib D. Behavioral vs drug treatment for urge urinary incontinence in older women: a randomized controlled trial. JAMA 1998;280:1995-2000.

4. Buser WD, Miner PB Jr. Delayed rectal sensation with fecal incontinence. Successful treatment using anorectal manometry. Gastroenterology 1986;91:1186-1191.

5. Chiarioni G, Bassotti G, Stanganini S, Vantini I, Whitehead WE, Stegagnini S. Sensory retraining is key to biofeedback therapy for formed stool fecal incontinence. Am J Gastroenterol 2002;97: 109-117.

6. Wald A, Tunaguntla AK. Anorectal sensorimotor dysfunction in fecal incontinence and diabetes mellitus. Modification with biofeedback therapy. N Engl J Med 1984;310:1282-1287.

7. Berghmans LC, Hendriks HJ, De Bie RA, van Waalwijk van Doorn ES, Bo K, van Kerrebroeck PE. Conservative treatment of stress urinary incontinence in women: a systematic review of randomized clinical trials. Br J Urol 1998;82:181-191.

8. Koutsomanis D, Lennard-Jones JE, Roy AJ, Kamm MA. Controlled randomised trial of visual biofeedback versus muscle training without a visual display for intractable constipation. Gut 1995; 37:95-99.

9. Norton C, Chelvanayagam S, Wilson-Barnett J, Redfern S, Kamm MA. Randomized controlled trial of biofeedback for fecal incontinence. Gastroenterology 2003;124:1320-1329.
10. Heymen S, Jones KR, Ringel Y, Scarlett Y, Drossman DA, Whitehead WE. Biofeedback for fecal incontinence and constipation: the role of medical management and education (abstr). Gastroenterology 2001;120(suppl 1):A397.

11. Freeman RM, Baxby K. Hypnotherapy for incontinence caused by the unstable detrusor. Br Med J (Clin Res Ed) 1982;284:18311834.

12. Whitehead WE, Schuster MM. Irritable bowel syndrome: psychological and pharmacological treatment. In: Whitehead WE, Schuster MM, ed. Behavioral medicine. Orlando, FL: Academic Press, 1985:211-228.

13. Thompson WG. Placebos: a review of the placebo response. Am J Gastroenterol 2000;95:1637-1643.

14. Owens DM, Nelson DK, Talley NJ. The irritable bowel syndrome: long-term prognosis and the physician-patient interaction. Ann Intern Med 1995;122:107-112.

15. Drossman DA, Whitehead WE, Camilleri M. Irritable bowel syndrome: a technical review for practice guideline development. Gastroenterology 1997;112:2120-2137.

16. Borkovec TD, Nau SD. Credibility of analogue therapy rationales. J Behav Ther Exp Psychiatry 1972;3:257-260.

17. Guthrie E, Creed F, Dawson D, Tomenson B. A controlled trial of psychological treatment for the irritable bowel syndrome. Gastroenterology 1991;100:450-457.

18. Creed FH, Fernandes L, Guthrie E, Palmer S, Ratcliffe J, Read NW, Rigby C, Thompson DG, Tomenson B. The cost-effectiveness of psychotherapy and SSRI antidepressants for severe irritable bowel syndrome (abstr). Gastroenterology 2001;120:A115.

19. Whorwell PJ, Prior A, Faragher EB. Controlled trial of hypnotherapy in the treatment of severe refractory irritable-bowel syndrome. Lancet 1984;2:1232-1234.

20. Burnette MM, Adams HE. Detection of noncontingent feedback in EMG biofeedback. Biofeedback Self Regul 1987;12:281-293.

21. Blanchard EB, Peters ML, Hermann C, Turner SM, Buckley TC, Barton K, Dentinger MP. Direction of temperature control in the thermal biofeedback treatment of vascular headache. Appl Psychophysiol Biofeedback 1997;22:227-245.

22. Burgio KL, Robinson JC, Engel BT. The role of biofeedback in Kegel exercise training for stress urinary incontinence. Am J Obstet Gynecol 1986;154:58-64.

23. Burns PA, Pranikoff K, Nochajski TH, Hadley EC, Levy KJ, Ory MG. A comparison of effectiveness of biofeedback and pelvic muscle exercise treatment of stress incontinence in older communitydwelling women. J Gerontol 1993;48:M167-M174.

24. Shepherd AM, Montgomery E, Anderson RS. Treatment of genuine stress incontinence with a new perineometer. Physiotherapy 1983;69:113

25. Payne A, Blanchard EB. A controlled comparison of cognitive therapy and self-help support groups in the treatment of irritable bowel syndrome. J Consult Clin Psychol 1995;63:779-786.

Address requests for reprints to: William E. Whitehead, Ph.D., Center for Functional GI and Motility Disorders, Campus Box 7080, University of North Carolina at Chapel Hill, Chapel Hill, North Carolina 275997080. e-mail: William_whitehead@med.unc.edu; fax: (919) 966-6842. Supported by grant R01 DK57048 from NIDDK. 